University of Wollongong

Research Online

Faculty of Social Sciences - Papers (Archive) Faculty of Arts, Social Sciences \& Humanities

$1-1-2016$

Transition of children with disabilities into early childhood education and care centres

Jane D. Warren

University of Wollongong, jwarren@uow.edu.au

Wilma Vialle

University of Wollongong, wvialle@uow.edu.au

Roselyn M. Dixon

University of Wollongong, roselyn@uow.edu.au

Follow this and additional works at: https://ro.uow.edu.au/sspapers

Part of the Education Commons, and the Social and Behavioral Sciences Commons

Research Online is the open access institutional repository for the University of Wollongong. For further information contact the UOW Library: research-pubs@uow.edu.au 


\title{
Transition of children with disabilities into early childhood education and care centres
}

\author{
Abstract \\ This paper reports on findings from research which sought to understand, in the New South Wales (NSW) \\ context, the factors impacting on the transition into early childhood education and care (ECEC) centres \\ for children with disabilities from the perspective of both parents of children with disabilities and \\ educators in ECEC centres. The study aimed to identify successes and barriers, and consider potential \\ interventions and procedures that might increase the participation of children with disabilities in ECEC \\ centres. This paper will discuss findings from the educator perspective only, including 37 completed \\ questionnaires and semi-structured interviews from 10 teacher participants. Thematic analysis revealed \\ the importance of communication with parents, relationships with previous service providers, \\ opportunities for professional learning and organisational support.
}

\section{Keywords}

education, care, centres, disabilities, transition, early, into, children, childhood

\section{Disciplines}

Education | Social and Behavioral Sciences

\section{Publication Details}

Warren, J., Vialle, W. \& Dixon, R. (2016). Transition of children with disabilities into early childhood education and care centres. Australasian Journal of Early Childhood, 41 (2), 18-26. 


\title{
Transition of children with disabilities into early childhood education and care centres
}

\author{
Jane Warren \\ Wilma Vialle \\ Rose Dixon \\ University of Wollongong
}

\begin{abstract}
THIS PAPER REPORTS ON findings from research (Warren, 2013) which sought to understand, in the New South Wales (NSW) context, the factors impacting on the transition into early childhood education and care (ECEC) centres for children with disabilities from the perspective of both parents of children with disabilities and educators in ECEC centres. The study aimed to identify successes and barriers, and consider potential interventions and procedures that might increase the participation of children with disabilities in ECEC centres. This paper will discuss findings from the educator perspective only, including 37 completed questionnaires and semi-structured interviews from 10 teacher participants. Thematic analysis revealed the importance of communication with parents, relationships with previous service providers, opportunities for professional learning and organisational support.
\end{abstract}

\section{Introduction}

Australia's first National Quality Framework (NOF) for early childhood (ACECQA, 2011) was introduced in January 2012 to provide a consistent approach to high-quality early childhood education and care (ECEC) across Australia. Within this framework, a number of guiding documents support the inclusion of all children in ECEC services. Educators are encouraged to have high expectations of all children, including those with developmental disabilities; as well as current regulations identifying that inclusive practices must be followed (ACECQA, 2011). As a core part of the NQF, the Early Years Learning Framework (EYLF) provides 'a strong theoretical and philosophical foundation for respecting diversity and acting for equity and inclusion for all children in ECEC programs' (Moore, 2013 , p. 2). Prior to the introduction of the NQF, statistics revealed that children with disabilities made up 5.2 per cent of the population of children from birth to five years; however, children with disabilities in that same age bracket only made up 2.5 per cent of the children in approved care (Government of South Australia, 2009). This reflects previous research which found the percentage of children with disabilities accessing ECEC centres is significantly lower than the percentage of children without disabilities (Mohay \& Reid, 2006). Barriers to full and equitable participation and access of children with disabilities in
ECEC need to be identified to determine why the number of children with disabilities in ECEC centres is so limited. Transition into ECEC centres can lay the foundation for the success of inclusion in ECEC centres, which can then impact on further transitions, such as the transition to school. While there have been studies on transition into school, transition into ECEC centres-that is, non-compulsory education in Australia-is an under-researched area.

\section{Current landscape of early childhood education}

There is a growing body of research that confirms the importance of the early years for its role in lifelong learning and development (Government of South Australia, 2009; Kilburn \& Karoly, 2008; Papatheodorou, 2010; Schweinhart et al., 2005). While this is something that has been recognised for a long time, researchers are collectively providing evidence of the long-term benefits of attendance in an ECEC centre (D'Onise, Lynch, Sawyer \& McDermott, 2010; Schweinhart et al., 2005). This recognition is a foundation of the NQF and identified by the Australian Institute of Family Studies: 'The importance of the early years to children's lives is now beyond question. A good beginning is well recognised as the foundation for future development, health and well-being, not only in the early years, but also throughout life' (Hayes, 2006, as cited in, Elliott, 2006, p. vi). 
In addition, there are a number of other areas of early childhood that are now at the forefront of educational research. Findings from research into the formation of the brain have reinforced the important role of positive, supportive relationships in early childhood development (Moore, 2007). Research into how children learn, neural plasticity and critical periods of development of the brain support the opportunity for high-quality early childhood education for all children (Oberklaid, 2007). There is insurmountable evidence of the importance of early childhood education in all children's lives, including children with disabilities.

\section{The importance of inclusion of children with disabilities}

Inclusion is a practice in which early childhood educators are encouraged to explore new opportunities for children with and without disabilities in mainstream ECEC centres. Inclusion is promoted internationally in developed countries by both legislative mandates and societal values. The belief that children with disabilities should participate alongside their peers without disabilities within natural environments is a shared value for many ECEC programs worldwide (Betts \& Lata, 2009; Cologon, 2013; Frankel \& Gold, 2007; Frankel, Gold \& Ajodhia-Andrews, 2010; Odom, Teferra \& Kaul, 2004; Runswick-Cole, 2011). Although the context for each specific country varies, the underlying principles and challenges for implementation of inclusive practices remain strikingly similar (Frankel et al., 2010).

The Convention on the Rights of Persons with Disabilities (CRPD) was adopted in 2006 at the United Nations (UN) Headquarters in New York, and was opened for signatories in 2007. Australia joined other countries around the world in 2008 in a global effort to promote the equal and active participation of all people with disability (Australian Government, 2015). The CRPD asserts that 'all children with disabilities have human rights and freedoms equal to those of any other child' (UN, 2006). This coincides directly with the UN Convention on the Rights of the Child that states that all children have fundamental rights to an education and to experience full involvement in society (UN, 1989). Both are fundamental to inclusion in ECEC centres. There has been gradual movement toward inclusive education in the past four decades (Cologon, 2013). What remains a concern is the policy-practice gap, which is highlighted by research focusing on policy and practice in Australia being 'hampered by a number of factors including a current lack of shared or common meaning for "inclusive education"' (Cologon, 2013, p. 9).

The joint position statement from the US in 2009, with contributions from both the Division for Early Childhood (DEC) and the National Association for the Education of Young Children (NAEYC), identifies three defining features for inclusion. These include access, participation and supports (DEC \& NAEYC, 2009). In Australia, the National
Early Childhood Development Strategy was developed in 2009 with a key outcome focused on children benefitting from better social inclusion and reduced disadvantage (COAG, 2009, p. 13), which led to the introduction of the NQF in 2012. Following this, a joint position statement by Early Childhood Australia (ECA) and Early Childhood Intervention Australia (ECIA) was released in August 2012, which sets out a shared commitment to inclusion in early childhood, with the purpose of creating a vision for highquality inclusive practices in ECEC (ECA \& ECIA, 2012). It was developed in recognition that:

Every child is entitled to access and participate in early childhood education and care programs which recognise them as active agents in their own lives and learning, respond to them as individuals, respect their families as partners and engage with their diverse backgrounds and cultures (ECA \& ECIA, 2012, p. 2).

The foundation of this position statement is children's rights and ethical practice. 'It will assist everyone in ECEC services as well as support professionals to fully include children with a disability and to achieve high quality outcomes for all children' (ECA \& ECIA, 2012, p. 1). This position statement is a pivotal initiative based on the principle that children with a disability have the same rights as all children.

In early childhood in particular, the importance of inclusion has been at the forefront of current initiatives and research. Back in 2004, an extensive literature review by Odom and colleagues revealed a number of findings, including that positive outcomes were reported for children with disabilities as well as typically developing children in inclusive settings (Odom et al., 2004). This focus on inclusion has been continued with extensive literature reviews in Australia in more recent times (Cologon, 2013; Moore, 2013).

Early intervention is recognised as being crucial. There is a growing evidence base for the use of supported inclusion in mainstream settings as a key method of intervention (Coulthard, 2009). In prior-to-school settings, it has been found that 'early childhood interventions of high quality have lasting effects on learning and motivation' (Heckman, 2004, p. 1). As early intervention provides a solid foundation for the child's learning and development, it is essential that services for young children with disabilities begin as early as possible to promote healthy development and minimise the negative trajectory of the disability. However, it is essential to note that enrolment in an ECEC centre does not automatically result in inclusion. A range of adaptations and intervention approaches must be considered to encourage engagement, participation and a sense of belonging for all children (Buysse, 2011). Given this importance of early intervention, it is imperative that all families of children with disabilities have access to a range of early intervention options, including accessing ECEC centres. However, research would suggest this is not always the case (Shaddock, 2006). 


\section{Transition into ECEC centres}

While there is extensive literature on transition to school, and sometimes on transition of children with disabilities into school, there is a dearth of literature on transition into ECEC centres for either typically developing children or young children with disabilities, despite this being recognised as an important transition (Hare \& Anderson, 2010). Although transition to kindergarten for children with disabilities has not been widely researched, the past decade has seen far more attention being paid to this area (Fenlon, 2005; Janus, Lefort, Cameron \& Kopechanski, 2007). A positive transition and ongoing inclusion in an ECEC centre will provide the most positive foundation for establishing a positive trajectory for the child's development. While this knowledge is becoming increasingly more widespread, the transition into ECEC centres continues to be a neglected area within the research and literature.

Given the lack of research, the purpose of this study was to determine what factors impact on the transition of a child with disabilities into an ECEC centre.

\section{The study}

The question, 'What are the issues involved in the transition of children with disabilities into early childhood education and care (ECEC) centres, according to the perceptions of key stakeholders?', guided the study. In the wider study, perceptions of both parents of children with disabilities and educators within ECEC centres were included as they are the main stakeholders in this process, and related to Bronfenbrenner's ecological model which was the theoretical foundation for the current study (Bronfenbrenner, 1986). However, this paper addresses the issues involved in the transition of children with disabilities into ECEC centres from the perspective of the educators only. It seeks to provide a platform on which useful documents and guidelines are built.

\section{Method}

Mixed-method research was selected to gather data on the experiences of a larger sample as well as an in-depth understanding of the lived experiences of a smaller cohort. This method has been used for previous studies on inclusion of children with disabilities (Li, Marquart, \& Zercher, 2000), as it enables a broader perspective and deeper understanding than could be obtained through a single research method (Mertens, 2005).

\section{Site}

The study was conducted in the Illawarra area of NSW, Australia, and participant selection was carried out purposefully. The researcher has had a long-term engagement in the early childhood sector in the Illawarra which resulted in a number of connections and collegial relationships in both the disability and early childhood sector, allowing for the easy securing of participants. The ECEC centres selected represented stand-alone centres, as well as centres representing the three key service providers in the Illawarra.

\section{Participants}

During July 2009, questionnaires were distributed by mail to all ECEC centres within the Wollongong phonebook, which included long day care, occasional care centres and preschool settings in the defined research area. Stamped envelopes were included to encourage responses. There were a total of 125 questionnaires mailed out, and between August and October 2009, 37 responses were received. This represents almost a 30 per cent response rate. The researcher made no attempt to gain more responses, as it was believed the most honest responses would have come from those who voluntarily chose to participate. The percentage of responses was consistent with the expected response rate of 10-50 per cent for mailed questionnaires (McBurney \& White, 2007).

From the 37 responses received, 22 people consented to a follow-up interview, and 10 were selected from these for the interview to provide a balanced approach to the number of parent responses. This represents the other component of this research study, which is outside the scope of this paper. While the initial questionnaire did not specify gender, all respondents who consented to an interview were female. Without intention, all educators who were selected for an interview had at least 10 years' experience in ECEC. The information obtained in the questionnaires informed subsequent data collection by providing the basis of content for interview questions.

\section{Data collection instruments}

The questionnaire began with three initial questions that related to the centre, including the age of children enrolled and centre type. A list was included for educators to select which areas of disability were experienced by children they had currently, or previously, enrolled within their centre. The categories for selection are outlined in Table 1.

Table 1. Areas of disability

\begin{tabular}{|l|l|l|}
\hline $\begin{array}{l}\text { Behavioural } \\
\text { difficulties }\end{array}$ & $\begin{array}{l}\text { Language } \\
\text { difficulties or } \\
\text { delays }\end{array}$ & $\begin{array}{l}\text { Sensory } \\
\text { impairment }\end{array}$ \\
\hline $\begin{array}{l}\text { Emotional } \\
\text { difficulties }\end{array}$ & $\begin{array}{l}\text { Difficulty } \\
\text { communicating }\end{array}$ & $\begin{array}{l}\text { Other (please } \\
\text { specify) }\end{array}$ \\
\hline Cognitive delay & $\begin{array}{l}\text { Mobility } \\
\text { restrictions }\end{array}$ & \\
\hline
\end{tabular}

While it is recognised that all disabilities are unique, and no two children are the same, these categories were selected by the researcher to determine whether there were any areas of disability that educators had experience in. Due to the wide range of disabilities and the small scope of this study, these categories were an attempt to cluster areas of disability. 
Levels of support needs were identified, whether or not a termination of enrolment for a child with a disability had occurred and reasons for that. Educators were asked to identify reasons for successful communication between staff and parents, whether they felt transitions had been satisfactory and why or why not. The participant was then asked to indicate which items on the following list they felt would have assisted in a successful transition for a child with a disability into their centre. The list was created on the basis of existing literature, and included:

- establishing a communication dictionary (a summary of communication attempts by the child so the cues can be 'read' by educators)

- discussion of appropriate visuals for the child

- formulation of an individual plan

- more knowledge within staff regarding inclusion of children with additional needs

- willingness of educators to include the child

- more open communication

- working with parents to establish appropriate goals for their child.

Individual interviews with 10 early childhood educators were conducted in the educators' place of employment. These were selected purposefully based on accessibility and ensuring a range of centres were represented. This decision was made to improve the possibilities for generalisability when the services cover the range in the field rather than being focused on one service type only. The primary focus in the interviews was to use openended questioning to elicit the most comprehensive information. The proposed interview questions were common questions, with individual questions used to elaborate on particular issues where relevant. These related to expansion of questionnaire responses, as well as exploring reasons behind behaviours and practices. The content considered: areas of disability that presented the most challenge to educators and perceived reasons for this; educator attitudes toward inclusion of children with disabilities and possible reasons; transition processes and procedures and their level of success; and communication between educators and parents of children with disabilities that has occurred.

As with all other data collection methods, the participant was asked if there was anything else they wanted to add at the end. These interviews were audio-recorded and transcribed by the researcher for accuracy of information gathered.

\section{Ethics}

The University of Wollongong Human Research Ethics Committee granted ethics approval (HE09/034) prior to the commencement of the research. When dealing with opinions of people, it is essential that an honest and accurate account is reflected by the researcher. Consideration of how to best represent early childhood educators was paramount.

\section{Findings and discussion}

Findings from multiple data collection methods are interwoven in this paper, with questionnaire responses identified as, for example, EQ15, and interview participant educators identified as E1, E2, to E10. Questionnaires revealed some key findings that were explored further in the individual interviews. The first question revealed specific areas of disability that were currently, or had previously been, represented in centres. Educators identified children with particular areas of disability; the total numbers of children with each area of disability are represented in Figure 1, with language and communication difficulties being the most prevalent. Cognitive delay and behavioural issues were also significant. Responses listed by educators in the 'Other' category included Autism Spectrum Disorder (ASD), Down Syndrome, medical issues, being tube fed, Foetal Alcohol Syndrome, global delays and Prader Willie Syndrome. However, some of

Figure 1. Areas of disability represented in centres

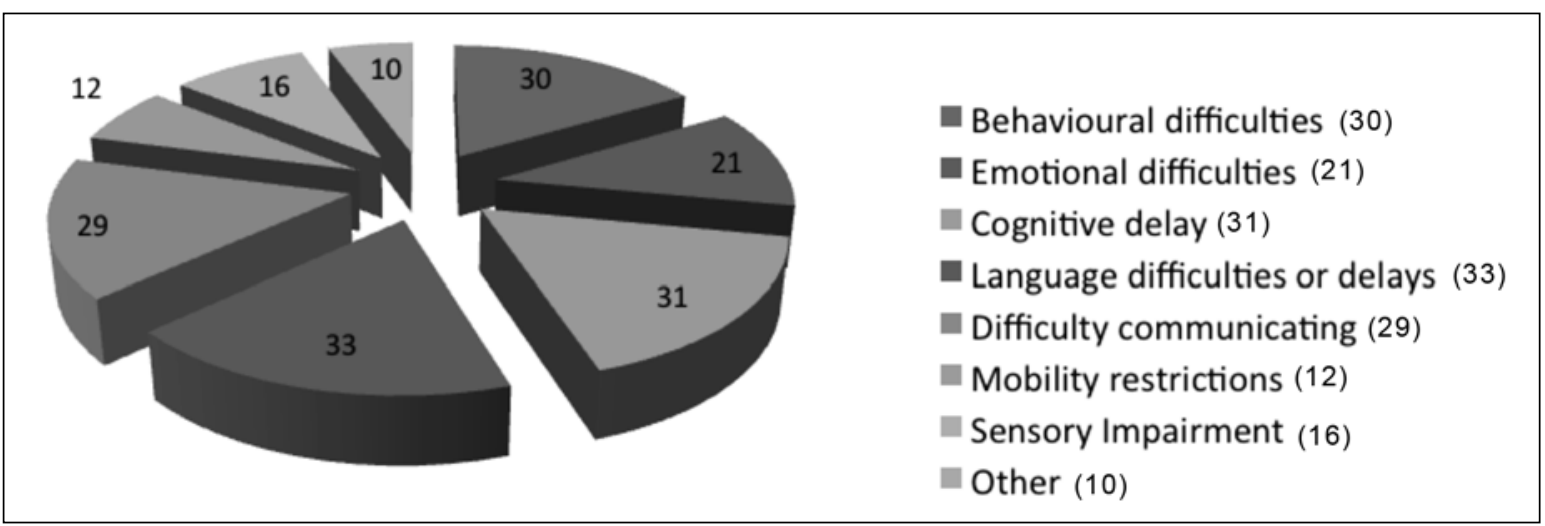


these diagnosed disabilities may have been placed into one of the given areas by other participants.

The remaining questions addressed specific elements relating to the transition process, which was also elaborated on in the interviews. Educators were asked what they felt impacted most on a successful transition into the centre. From the educators' perspective, a parent being honest about their child had a very positive influence on the transition of the child into the centre, as there are no 'surprises' and strategies can be put into place straight away to ensure the child is supported from the beginning:

I find that parents are very keen to share information about the child so the service can be as informed as possible to best meet the needs of the child (EQ24).

Another key finding from the educators in this study was their view that when they were open with the families, treating them equally regardless of the children's disability, a more positive transition occurred. Educators also believed that positive transitions for children, families and the educators themselves can result from having individual meetings with families, which may include the construction of an Individual Education Plan (IEP). It would appear that a comprehensive orientation which establishes the relationship with the family would be beneficial for all involved. In addition, transition visits prior to full enrolment, and the inclusion of initiatives such as communication books and communication dictionaries would lay the foundation for more positive relationships and ongoing communication.

Educators indicated that the biggest barriers to effective communication arose when parents were either in denial about their child's needs, or when they were unaware of the extent of the child's needs:

Some parents preferred not to discuss anything and in some cases appeared to be in denial about any problems their child was experiencing (EQ16).

While this may appear to be a negative response, educators explained that the lack of information gained from families sometimes left them in a precarious position. The strength of support educators can offer is often dependent on honest communication with families.

Transition was more successful when educators were willing to liaise with other organisations and practitioners with whom the child was already familiar. Creating connections with other teams or professionals was also identified as important for having the best opportunity to meet the needs of the child:

I do try and invite as many other people that are involved with that child as possible or sometimes they will invite me to their meetings (E10).

Over time, the parents have hopefully developed trusting and supportive relationships with these practitioners. When these organisations or practitioners are involved in the ECEC centre from the start, parents will have more confidence that the educators will have a better understanding about their child. It would also be reassuring to families that the educators are taking an active role in developing their understanding and expanding their knowledge. The importance of the partnerships between family and ECEC centres sits centrally within the mesosystem of Bronfenbrenner's ecological model (1986). Many children with disabilities have strong links to support services or therapy teams, so these people are already enmeshed into the closest layers of the ecological model.

Good communication between educators and parents arose as a recurring theme throughout this research, which supports findings from previous studies. Coulthard (2009) highlighted the importance of working within a family-centred approach, where communication is an essential component. Additional studies explored a range of issues relating to inclusion and identified communication between educators and parents of children with disabilities as being crucial (Fenlon, 2005; Mclntyre, Blacher \& Baker, 2006). In addition, communication between parents and educators is a fundamental component of the EYLF (DEEWR, 2009). It is not suggested that the lack of communication is dependent on the family only-open communication must be reciprocal between both the family and the educators.

Educators identified a number of specific strategies and processes that would assist in successful transitions. These include some specific documents as well as strategies to increase communication, which are outlined in Figure 2.

Areas of disability that educators identified as being most challenging were clustered by the researcher into four groups based on responses: high support needs; parents not acknowledging their child has a disability; children without a diagnosis; and challenging behaviour. High support needs imply both breadth and depth of need, which relates to both complexity and intensity (Rankin \& Regan, 2004). High support needs included medical issues, feeding concerns and mobility restrictions. Medical needs were mentioned as providing a challenge, as many educators felt that they challenged their duty of care and sometimes bordered on nursing. One educator stated:

You feel very responsible and it is scary. If something goes wrong, do I have the skills to deal with it? (E5).

Other educators agreed that medical needs were definitely outside their area of expertise and knowledge, and it was a challenge to determine how competent they were to deal with these issues. A number of educators mentioned feeding issues. One educator identified that coming across a child who required tube feeding was quite confronting. Another educator commented on a child with multiple disabilities who was orally fed but required significant support:

I wasn't sure if I was choking him or feeding him and I found it really distressing because I didn't know if 
Figure 2. Strategies or processes to assist success in transitions

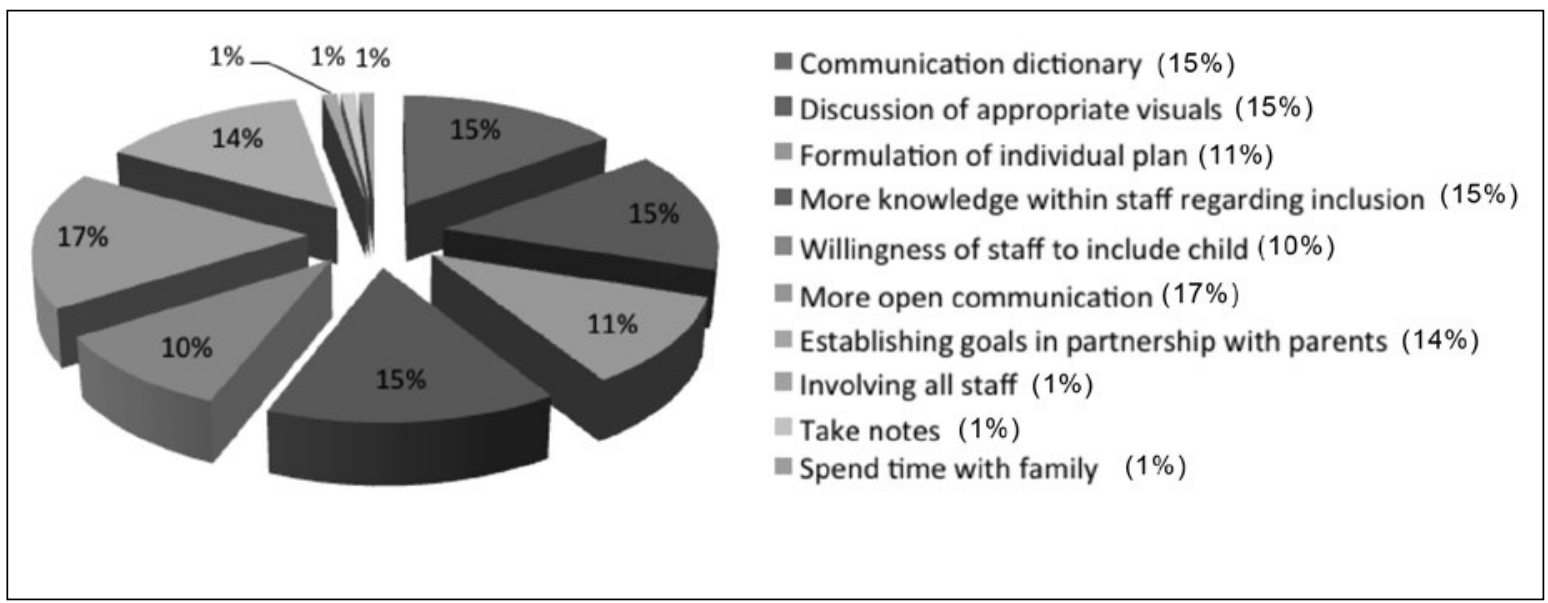

I should still be trying to put this food in when he seemed like he was choking (E6).

Two educators believed that mobility restrictions were physically and emotionally challenging. One commented that when a child presents with severe cerebral palsy, there are challenges with the equipment they require, as they use a wheelchair, or require particular seating:

We had one child with severe physical issues. He was hard to move, hard to lift (E1).

Parents not wanting to admit or acknowledge their child has a disability were also highlighted as being a significant challenge for educators, with seven of the 10 respondents mentioning this. It was acknowledged by one educator that it sometimes seems that some parents find it difficult to accept that their child has some sort of disability, and it takes persistence on the part of the educator while the parent develops this acceptance. The lack of awareness from some parents often meant that the educator was the first one to mention the difficulties that the child experienced. Six educators reported that children without a diagnosis provided an additional challenge. As educators are not responsible or ethically able to diagnose areas of disability, it appeared that a lack of information from the family made it difficult for some educators to know where to begin in relation to concerns they may have about the child. The lack of available funds when there is no diagnosis was identified as difficult for services and created additional challenges for educators within their existing workloads. One educator commented that when the centre is not receiving funding for a child, 'it compromises a child's experience and the other children, and the other staff. If a child is under-funded for what they need, it affects their full participation' (E5). This links strongly to the importance of the ecological model which provided the theoretical foundation underpinning this research.
Four educators commented on the impact that challenging behaviour has in the service. All mentioned safety issues that relate to managing challenging behaviour within the centre:

It is the most difficult to manage in a safe environment and sometimes the most difficult to understand (E2).

Another educator commented:

Non-compliance in behaviour is definitely our biggest one because those children are more aggressive and you are dealing with risk management and if people have not had experience with violence, it can be very stressful (E7).

This supports findings of previous research which found that challenging behaviours of children with disabilities is rated by staff as one of the most significant sources of work-related stress (Robertson et al., 2005). The difficulties educators attributed to challenging behaviours can often be linked to characteristics of a child's disability-for example, the lack of mainstream communication strategies a child may have. While this may be seen as something that needs 'fixing', we need to consider the social model of disability here which would suggest that the issues are in the perception of others rather than the child's skills (Cologon, 2015). It would also appear that positive relationships between parents and educators would assist in understanding individual children's cues, again highlighting the importance of the ecological model.

Educators all agreed that in general there was a positive attitude toward including children with disabilities. However, these responses would be expected from willing participants. A number of reasons were given for positive attitudes, but also a number of variables were identified which impact on this positive attitude. Each educator identified at least one of the variables listed below, with all participants citing more than one. The distribution was 
relatively even, with all being identified as very significant influences on attitudes of other educators. These include balancing and sharing the load, confidence, training, support from a larger organisation or network and experience. One educator commented that, 'Confidence and competence seems to come from training and experience' (E2). Another educator elaborated on this response, 'If people haven't had any training, or they don't have any experience, there are definite differences-they lack confidence, and sometimes competence' (E7). In relation to experience, one educator identified that, 'Over time the staff build up capacity' (E5).

Positive relationships between management and educators were identified as being important. Educators felt it can be challenging for them when they are trying to convince their committee about the importance of meeting the needs of the child. Being part of an 'umbrella organisation' was identified from someone in one of these organisations as being really essential to the level of support received:

The support we get [from our organisation] is definitely valuable (E7).

Training was overwhelmingly identified as being an essential characteristic of including a child with disabilities within the service:

Professional development really does help. You feel a bit more empowered (E5).

It was also identified that despite initial training, you must be aware of your limitations:

Sometimes you have to realise that even with experience you come across something you don't know, and need to learn about (E1).

The training comments did link to attitude, with one educator commenting that, 'if you are open to learning; that is probably more important than your initial training' (E4).

Positive attitudes of educators toward children with disabilities are essential to the success of the transition. In this research, educator participants all believed there was generally a positive attitude to children with disabilities within their service, which was expected given the voluntary participation of these educators. It is less likely that an educator who is not positive toward children with disabilities would have chosen to participate in this research. It would appear that teacher attitudes are one of the most influential variables in the success of inclusion. Having policies in place within the centre was identified as making it easier for everyone to understand the priorities and guidelines of the centre:

It is a matter of making sure policies are in place, and also everyone being able to read that policy, understand it and interpret it to other people (E9).

The findings from the current research led to recommendations for both policy and practice.

\section{Recommendations for policy}

Every ECEC centre needs a policy that relates to inclusion of children with disabilities, even if it is part of a broader policy addressing inclusion in relation to a range of areas of diversity. However, the latter may not contain the requisite specific information. Each centre should have a specific policy that details the rationale for including children with disabilities, supported by legislative and ethical guidelines. In addition, specific information should be included which relates to how children with disabilities can be included. Practical strategies will support the overall purpose and significance of inclusion. Of specific benefit would be to include information that supports the transition of the child into the centre. The 2012 joint position statement on the Inclusion of Children with a Disability in Early Childhood Education and Care sets out a shared commitment to inclusion, and provides a framework for development and implementation of policy and programs designed for young children (ECA \& ECIA, 2012). This position statement is a powerful and crucial document, which could be the basis for a centre-based policy. It addresses rights and the responsibility of centres to ensure these rights are positioned centrally for all children. This position statement identifies the need for action, reflective of a common concern to build the capacity of early childhood educators and assist professionals to support high-quality inclusion (ECA \& ECIA, 2012). This research project takes one small step toward positive action in this area.

\section{Recommendations for practice}

Findings from the current research identified a number of issues that arose for educators, and the impact of these on the educators' ability to provide a solid, positive transition into an ECEC centre for a child with a disability and their family. While it is not suggested that there is a quick solution to full inclusion for all children, this research would suggest that some more guidance for educators may be of assistance, such as an information package for educators in both paper and electronic format. This package could include some theoretical foundation for the importance of inclusion, as well as pedagogical approaches to ensure a successful transition into the ECEC centre. In addition, templates for specific processes, such as communication dictionaries, IEP goal setting and other orientation information could be included. Inclusion of ways to reassure parents and explain policy, procedures and practices which will support the child are necessary, such as embedded intervention (McWilliam \& Casey, 2008). Local information, such as therapy contacts, support agencies for both parents and educators, and organisations that may benefit children, parents and educators is needed. This may become increasingly useful for parents with the rollout of the National Disability Insurance Scheme (NDIS) over the next few years. 
While some of these documents already exist within ECEC centres or wider support services, creating a central document may benefit educators, so information is accessible in one place. It is essential that this information package be developed in a 'user-friendly' way, so information is comprehensive, yet accessible to all educators, irrespective of qualifications and experience. This information package needs to be presented in sections that are easy to find and read. Planning meetings are underway to develop this resource to assist educators in ECEC centres. While it is not perceived this will be a 'solution', it may provide some educators with additional knowledge and strategies to better place them to include children from the outset.

\section{Limitations}

It is important to recognise that this research study is restricted to the in-depth experience and opinion of 10 educators from ECEC centres. It could be assumed that those who responded were interested in the area of inclusion of children with disabilities. The 37 educators who responded by completing the initial, anonymous questionnaires may have represented centres with a higher percentage of enrolment of children with disabilities than would be expected if it was required by all centres in the specified geographical location to respond. The 10 educators selected for interviews were selected to represent a range of ECEC centres and had consented to be interviewed. Again, it could be concluded that the attitudes, experience and responses of these voluntary participants would be reflective of a more inclusive educator.

\section{Conclusion}

The value of early childhood education as a foundation for lifelong learning and wellbeing is well established within the literature (Government of South Australia, 2009; Shearer, 2008). In Australia, the number of children using ECEC centres has almost quadrupled in the past 20 years (ABS, 2011). However, it would appear that this is not necessarily the case for children with disabilities, as outlined in the introduction. This research has identified a number of barriers which may contribute to this inconsistency.

From a social justice perspective, it is essential that all children have the opportunity to be engaged in positive ECEC experiences. Inequity still exists, despite the significant legislation and documentation that should ensure the rights and opportunities for all children are fair. The transition into ECEC centres for children with disabilities will be the first formal transition, whether this occurs at six months, or four years of age. The importance of success in this transition cannot be underestimated, as the experience in early childhood will be the foundation for all subsequent educational and social opportunities for the child. The findings from this research have highlighted the importance of the process of transition into the ECEC centre and the impact this will have on the subsequent inclusion of the child with a disability.
The recommendations arising from this research have the potential to improve the process of transitioning into an ECEC centre for children with disabilities. A positive approach by parents of children with disabilities, and educators within ECEC centres, will ensure that the rights of every child are respected and the inclusion of all children is an achievable and enriching process for all involved.

\section{References}

Australian Bureau of Statistics (ABS). (2011). Childhood education and care, Australia: Summary of findings. Retrieved 10 June, 2013, from www.abs.gov.au/AUSSTATS/abs@.nsf/ Previousproducts/4402.0Main\%20Features2June\%202011?opend ocument\&tabname $=$ Summary \&prodno $=4402$.0\&issue $=$ June $\% 20$ $2011 \&$ num $=\&$ view $=$

Australian Children's Education and Care Quality Authority (ACECQA). (2011). National Quality Framework. Sydney: ACECQA. Retrieved 10 June, 2013, from www.acecqa.gov.au/national-quality-framework.

Australian Government. (2015). Convention on the Rights of Persons with Disabilities. Retrieved 10 June, 2013, from www.ag.gov.au/RightsAndProtections/Human Rights/Pages/UnitedNationsConventionontherights ofpersonswithdisabilities.aspx.

Betts, J., \& Lata, D. (2009). Inclusion of children with disabilities: The early childhood imperative. UNESCO Policy Brief on Early Childhood, No. 46. Paris: United Nations Educational, Scientific and Cultural Organization.

Bronfenbrenner, U. (1986). Ecology of the family as a context for human development: Research perspectives. Developmental Psychology, 22(6), 723-742.

Buysse, V. (2011). Access, participation, and supports: The defining features of high-quality inclusion. Zero to Three, 31(4), 24-31.

Cologon, K. (2013). Inclusion in education: Towards equality for students with disability. Children with Disability Australia. Sydney: Children and Families Research Centre, Institute of Early Childhood, Macquarie University. Retrieved 26 February, 2015, from http://apo. org.au/node/36129

Cologon, K. (2015). Better together: Inclusion in the early years. Early Childhood Intervention Australia (NSW Chapter Conference). Sydney, Australia. 28-29 May, 2015. Keynote presentation. Retrieved 30 August, 2015, from www.ecia-nsw.org.au/conferencesevents/ ecia-conferences.

Coulthard, N. (2009). Service trends and practitioner competencies in early childhood intervention: A review of the literature. Box Hill, Vic.: Scope Vic Ltd, Victorian Chapter of ECIA.

Council of Australian Governments (COAG). (2009). Investing in the early years - A national early childhood development strategy. Canberra: Commonwealth of Australia.

Department of Education, Employment and Workplace Relations (DEEWR). (2009). Belonging, Being \& Becoming: The Early Years Learning Framework for Australia. Canberra: Commonwealth of Australia. Retrieved 8 June, 2015, from https://docs.education.gov. au/system/files/doc/other/belonging_being_and_becoming_the_early_ years_learning_framework_for_australia.pdf.

Division for Early Childhood (DEC)., \& National Association for the Education of Young Children (NAEYC). (2009). Early childhood inclusion: A joint position statement of the Division for Early Childhood (DEC) and the National Association for the Education of Young Children (NAEYC). Chapel Hill, NC: The University of North Carolina, Frank Porter Graham Child Development Institute. Retrieved 30 March, 2016, from www. naeyc.org/files/naeyc/file/positions/DEC_NAEYC_EC_updatedKS.pdf. 
D'Onise, K., Lynch, J. W., Sawyer, M. G., \& McDermott, R. A. (2010). Can preschool improve child health outcomes? A systematic review. Social Science \& Medicine, 70(9), 1423-440. doi: 10.1016/j.socscimed.2009.12.037

Early Childhood Australia (ECA)., \& Early Childhood Intervention Australia (ECIA). (2012). Position statement on the inclusion of children with a disability in early childhood education and care. Retrieved 25 November, 2015, from www.earlychildhoodaustralia.org. au/wp-content/uploads/2014/06/ECA_Position_statement_Disability_ Inclusion_web.pdf.

Elliott, A. (2006). Early childhood education: Pathways to quality and equity for all children. Australian Education Review. Camberwell, Vic.: Australian Council for Educational Research. Retrieved 15 November, 2015, from http://research.acer.edu.au/cgi/viewcontent. cgi?article $=1003 \&$ context $=$ aer.

Fenlon, A. (2005). Paving the way to kindergarten for young children with disabilities. Young Children, 60(2), 32-37.

Frankel, E. B., \& Gold, S. (2007). Principles and practices of early intervention. In I. Brown \& M. Percy (Eds.), A comprehensive guide to intellectual and developmental disabilities (pp. 451-466). Baltimore, MD: Brookes.

Frankel, E. B., Gold, S., \& Ajodhia-Andrews, A. (2010). International preschool inclusion: Bridging the gap between vision and practices. Young Exceptional Children, 13(5), 2-16.

Government of South Australia. (2009). A strategic assessment of the children's services industry: A paper prepared for the children's services subcommittee of the community and disability services ministers' advisory council. Adelaide: Government of South Australia. Retrieved 10 June, 2012, from www.sprc.unsw.edu.au/media/SPRCFile/14_Report_ StrategicAssessmentofChildrensServicesIndustry.pdf.

Hare, J., \& Anderson, J. (2010). Transitions to early childhood for Indigenous children and families in Canada: Historical and social realities. Australasian Journal of Early Childhood, 35(2), 19-27.

Heckman, J. J. (2004). Invest in the very young. In R. E. Tremblay, R. G. Barr \& R. DeV. Peters (Eds.), Encyclopedia on Early Childhood Development (online). Montreal, Canada: Centre of Excellence for Early Childhood Development. Retrieved 22 May, 2012, from www. child-encyclopedia.com /pages/PDF/HeckmanANGxp.pdf.

Janus, M., Lefort, J., Cameron, R., \& Kopechanski, L. (2007). Starting kindergarten: Transition issues for children with special needs. Canadian Journal of Education, 30(3), 628-648.

Kilburn, R., \& Karoly, L. (2008). The economics of early childhood policy: What the dismal science has to say about investing in children. Santa Monica, CA: RANF Corporation.

Li, S., Marquart, J. M., \& Zercher, C. (2000). Conceptual issues and analytic strategies in mixed method studies of preschool inclusion. Journal of Early Intervention, 23(2), 116-132.

McBurney, D. H., \& White, T. L. (2007). Research methods (7th ed.). Belmont, CA: Wadsworth Publishing.

Mclntyre, L. L., Blacher, J., \& Baker, B. L. (2006). The transition to school: Adaptation in young children with and without intellectual disability. Journal of Intellectual Disability Research, 50(5), 349-361.

McWilliam, R. A., \& Casey, A. M. (2008). Engagement of every child in the preschool classroom. Baltimore, MD: Paul H. Brookes Publishing Co

Mertens, D. (2005). Research and evaluation in education and psychology (2nd ed.). Thousand Oaks, CA: Sage Publications.

Mohay, H., \& Reid, E. (2006). The inclusion of children with a disability in child care: The influence of experience, training and attitudes of childcare staff. Australian Journal of Early Childhood, 31(1), 35-42.
Moore, T. (2007). The nature and role of relationships in early childhood intervention services. Second conference of the International Society on Early Intervention. Zagreb, Croatia. 14-16 June. Retrieved 28 July, 2013, from www.rch.org.au/uploadedFiles/ Main/Content/ccch/TM_ISEIConf07_Nature_role_rships.pdf

Moore, T. (2013). Strengthening inclusive practices in early childhood intervention services: background paper. Sydney: Early Childhood Intervention Australia (NSW Chapter) Inc. Retrieved 14 August, 2014, from www.ecia-nsw.org.au/documents/item/1062.

Oberklaid, F. (2007). Brain development and the life coursethe importance of the early caretaking environment. National Childcare Accreditation Council (NCAC). Quality counts-responsive and effective child care conference, National Childcare Accreditation Council (NCAC). Melbourne, Australia. September 2007. Extract from Keynote presentation. Retrieved 6 May, 2010, from http://ncac. acecqa.gov.au/educator-resources/pcf-articles/Brain_Development Life_Course_Dec07.pdf.

Odom, S. L., Teferra, T., \& Kaul, S. (2004). An overview of international approaches to early intervention for young children with disabilities and their families. Young Children, 59(5), 38-43.

Papatheodorou, T. (2010). Being, belonging and becoming: Some worldviews of early childhood in contemporary curricula. Forum on Public Policy Online, 2010(2), September 2010. Retrieved 19 October, 2012, from http://forumonpublicpolicy.com/spring2010. vol2010/papers2010vol2.html.

Rankin, J., \& Regan, S. (2004). Meeting complex needs: The future of social care. London: Turning Points/Institute of Public Policy Research (IPPR).

Robertson, J., Hatton, C., Felce, D., Meek, A., Carr, D., Knapp, M., \& Lowe, K. (2005). Staff stress and morale in community-based settings for people with intellectual disabilities and challenging behaviour: A brief report. Journal of Applied Research in Intellectual Disabilities, 18(3), 271-277. doi: 10.1111/j.1468-3148.2005.00233.x

Runswick-Cole, K. (2011). Time to end the bias towards inclusive education? British Journal of Special Education, 38(3), 112-119. doi: 10.1111/j.1467-8578.2011.00514.x

Schweinhart, L. J., Montie, J., Xiang, Z., Barnett, W. S., Belfield, C. R., \& Nores, M. (2005). Lifetime effects: The HighScope Perry Preschool study through age 40 (Monographs of the HighScope Educational Research Foundation, 14). Ypsilanti, Ml: HighScope Press.

Shaddock, T. (2006). Disability or diversity? Encouraging true inclusion. Every Child, 12(3), 12. Canberra: Early Childhood Australia.

Shearer, J. (2008). Early childhood transition for children with a disability: Focusing on children's centres for early childhood development and parenting. Adelaide: Ministerial Advisory Committee.

United Nations (UN). (1989). Convention on the Rights of the Child. Geneva, Switzerland: UN. Retrieved 17 January, 2012 from www.unicef.org/crc.

United Nations (UN). (2006). Convention on the Rights of Persons with Disabilities. Geneva, Switzerland: UN. Retrieved 17 January, 2012, from www.un.org/disabilities/convention/conventionfull.shtml.

Warren, J. (2013). Transition of children with disabilities into early childhood education and care centres (Doctor of Education Thesis). School of Education, University of Wollongong, Wollongong, NSW, Australia. Retrieved 14 March, 2014, from http://ro.uow.edu.au/ theses/3995. 
Copyright of Australasian Journal of Early Childhood is the property of Early Childhood Australia and its content may not be copied or emailed to multiple sites or posted to a listserv without the copyright holder's express written permission. However, users may print, download, or email articles for individual use. 